\title{
The Cologne-Cleveland librarian exchange
}

\author{
By Klaus Peters, Hannelore B. Rader, and Alice Reviere Smith
}

\section{Two librarians sbare their exchange experiences}

n 1988 Cleveland State University (CSU) Library hosted it's first librarian exchange with the University of Heidelberg (CERL News, March 1989). This proved to be a very successful experience for both librarians involved. Professional information was exchanged, different customs were observed, and new ideas were generated. Staffs in both libraries were invigorated through this relatively short exposure to a librarian from another country. Therefore, when in October of 1990 a law librarian from the University of Cologne became interested in doing a professional exchange with an academic librarian in the United States, it was decided to pursue the matter. Arrangements were finalized in the summer of 1991. Klaus Peters from the University of Cologne spent August 19, 1991, to September 13, 1991, at Cleveland State University Library while Alice Smith went to the library at the University of Cologne during the same period. Following are summaries of their experiences.

\section{Klaus Peters comments}

American librarianship is considered exemplary in Germany. Therefore, many German librarians dream about doing a study trip to the United States to obtain additional knowledge about American librarianship in order to enrich their own knowledge. Each situation in which the individual finds himself or herself usually determines what particular interests he/ she will pursue. I am a law librarian and serve as the head of the user section. In addition to that, I teach library management and legal librarianship at the Library School for Library Science and Documentation in Cologne. I also consult and serve as representative to the Union of German Library Associations regarding copyright. I chair the working group on copyright for the European Research Librarians (LIBER), and have a very strong interest in learning about American library management, management of a law library, and collecting material about library copyright in the United States.

Approximately two years after becoming a librarian in 1988, I talked with Elizabeth Simon, the head of the Library Foreign Department in Germany to help me in the realization of $m y$ plan to organize a study trip to the United States. In October 1990 Hannelore Rader offered me a four-week exchange with a librarian from the Cleveland State University Library. A condition of this exchange was that the exchange partners would finance the trip and living expenses themselves by exchanging homes. The director of the University/City Library and the provost of the University in Cologne supported this exchange project. They allowed me a special four-week leave with pay and gave me my travel expenses. Thanks to the marvelous hospitality of my American colleagues, I had little opportunity to spend much money during my stay in the United States.

In Cleveland I lived with Gary Thompson, who was a wonderful host. I felt extremely comfortable in his house. He provided transportation and took me to many different places. Thanks to his marvelous help and support I did not need to rent an automobile. My exchange partner, Alice Smith, stayed in my apartment in Cologne. The apartment is approximately two kilometers from the library and can easily be 
reached by streetcar. I organized the program for the practicum for her.

My practicum, organized by Hannelore Rader, took my interests into consideration. I had an opportunity to participate at the weekly meetings and at an all-day retreat of the Management Team of the CSU library as well as to find out about all the departments in the library. Rader also took me to meetings of the statewide system, OhioLINK, and to meetings of regional resource sharing groups. She made it possible for me to spend several days at the Law Library at CSU as well as the Law Library at Case Western Reserve University. At the latter university I was also invited to lecture to students on the principles of German law and legal research. I was able to visit the Online Computer Library Center (OCLC) and the law firm

\section{It seemed to me that American}

\section{librarians on the average are bappier and more productive than German librarians.}

of Squires, Sanders and Dempsey in Cleveland. Wherever I went I was warmly welcomed and provided with much information and materials. These are my findings:

1. The principle of competition seems to be an important one in the university environment, much more so than in Germany. Competition also plays a role in defining the work of the libraries. Libraries feel that they have a very important role to play within the university and much to contribute to the competition. The CSU Library Management Team regularly discusses its strategies for the library to fulfill its mission within the university. During these discussions, they continually update and revise their very elaborate strategic plan. I was most impressed with the scientific level on which the long-term plans and goals of the library were discussed in an all-day management retreat. This was a learning experience for me about the use of the knowledge regarding information science for the practice of librarianship. Competition with all groups within the university is extremely important for the CSU Library. This competition, which ultimately resuits in budgeting allocations, continues to be a major challenge for the library director, who must aggressively portray the importance of the library, vis-à-vis the strategic goals and plans of the university.
2. While German academic librarians have a special civil service status and receive appointments for life, librarians at the CSU Library work under annual contracts. Librarians are evaluated according to established goals. Negative evaluations can conceivably result in non-renewal of contracts. The director is evaluated annually by the provost and every three years by the librarians. It is obvious that this particular system results in higher performance than the system in process in German academic libraries. It seemed to me that American librarians on the average are happier and more productive than German librarians. Perhaps one can explain this phenomenon with the competition principle deeply rooted in the American culture. I was amazed that the competition between colleagues did not result in a fight between all. On the contrary, teamwork and discussion seemed to be polite and to the point and were a major part of fulfilling one's work role on an everyday basis, much more so than in Germany. I interpret the open doors as signals of constant availability for conversation. The cooperation during the work time may explain that a number of librarians enjoy spending time away from work together. In this manner, I gained important insight into the American society and culture which helped me understand American librarianship.

My practicum at Cleveland State University Library was a wonderful experience for me both professionally and personally. The overwhelming hospitality which I received from Ms. Rader and her colleagues will remain in my memory forever. I can only hope that many of my American colleagues who took such good care of me in Cleveland will visit me in Cologne soon and provide me the opportunity to reciprocate.

\section{Alice Reviere Smith comments}

I am the Black Studies/Women Studies Librarian at Cleveland State University, serve on the Faculty Senate, and am very involved in ALA's Black Council. I traveled to Cologne on August 24, 1991, and returned on September 13 , 1991. Although the practicum was intended primarily for me to become familiar and acquainted with a university library and German academic librarianship in particular, I was able to visit and peruse other types of libraries including private and public. A visit was possible also to the major library school in the area of Cologne, the Fachhochschule fur Bibliotheksund Dokumentationswesen. Some areas of interest to me included the status of women in 


\section{Our Library of Congress Classification Cumulative Schedules and Indexes offer many advantages over the competition:}

- All LC Additions \& Changes are integrated with the basic LC schedules into one book, so that the cataloger only has to look in one place to find the most up-to-date classification numbers.

- Supplements are published quarterly, after the issuance of each LC Additions \& Changes List. The competition only supplements their schedules annually.

- Each schedule is attractively bound in a sturdy three-ring loose-leaf binder, with each major section divided by tabs for easy access.

\section{Compiled by Larry D. Dershem}

Class H Subclasses HM-HX Social Sciences

Class H Subclasses H-HJ Social Sciences: Economics

Class Z Bibliography and Library Science

Class J Political Science

Also available are the schedules and indexes for Class K Subclass KF (Law of the United States, 2v.,\$110); Subclass K (Law, General \$60); Subclass KD (Law of the United Kingdom and Ireland, \$75); Subclass KE (Law of Canada, \$75); Class KDZ, KG-KH (Law of the Americas, \$85); Class KJV-KJW (Law of France, \$85); Class KK-KKC (Law of Germany, \$95); and Class KJ-KKZ (Law of Europe, \$95). Estimated annual cost of updating: $\$ 52.50$ per volume

The process of cataloging library materials is time consuming and expensive. Why not give your technical services department the edge by purchasing our time saving LC Classification Cumulative Schedules and Indexes today!

To place an order, call or write:

\section{Fred B. Rothman \& Co.}

10368 West Centennial Road / Littleton, CO 80127 (800) 457-1986 
German librarianship; women studies as an area of collection development; bibliographic instruction for international and beginning students; use of computers, online, and $\mathrm{CD}$ ROMs in information and reference services; and preparation for academic librarianship in Germany as well as local and regional cooperation.

The University of Cologne and Cleveland State, although dissimilar in many in-

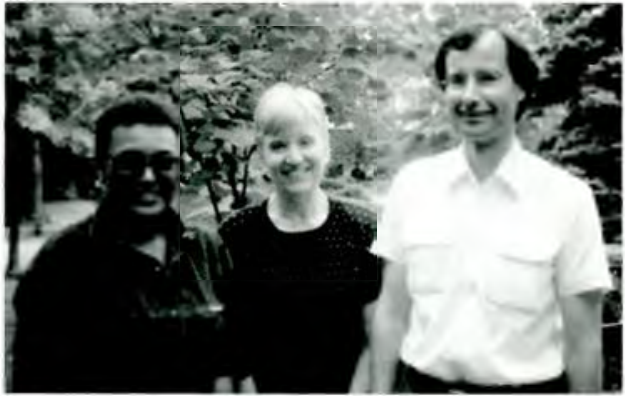

Alice Reviere Smith, Hannelore Rader, Klaus Peters have more money for use of the latest computer and media technology, use of personal computers for librarians and other staff, and use of various types of CD-ROMs for patrons.

Cleveland State, with one branch library (law), is quite a contrast to the University of Cologne which has 150 "institute" and "seminar" libraries which vary from the comprehensive and well-equipped stances-55,000 students versus 19,000 and a history dating back to the twelfth century versus the beginning of Cleveland State in 1965have similar problems and solutions. Fach is an urban institution with a large commuter population and are dependent on funding from the state (North Rhine/West-phalia and Ohio respectively). Although students at Cologne pay no tuition, CSU students are faced with rising tuition and other costs. Politics still enter the process at both institutions in funding for the libraries with the flagship universities in the respective state capitals seeming to receive a greater share. Cologne is beginning to develop and use computers for tasks which American libraries have been doing for some time, yet this is the state of North Rhine-Westphalia. Regional cooperation in the use of computer technology is developing in a data processing center for the academic libraries of the North Rhine-Westphalia; whereas, Cleveland State was one of the founding members of OCLC, Inc.

One area of vast difference is in preparation for and training of academic librarianship. German librarians are of three types with the highest level requiring a doctorate or master's in a subject area before entrance into library school. Academic librarians in the United States usually acquire subject master's and doctorates after acquiring the library school degree and some professional experience. Duties are also dissimilar with blurred lines between cataloging and acquisitions or collection selection at the University of Cologne. More emphasis is given to bibliographic instruction in American libraries with the predominantly open stacks concept in use.

The Central Public Library of Cologne and one of the private libraries I visited seem to medical library with a highly qualified staff to the smallest seminar library with a secretary as staff.

The trip was a revealing and interesting exercise for the comparison of two distinct philosophies of librarianship as well as concepts of an urban university and its libraries.

Once again, the international librarian exchange has enriched the CSU Library and its staff. One of the best things about the exchange is that staff have become aware of how much they have accomplished in recent years and how global librarianship has become.

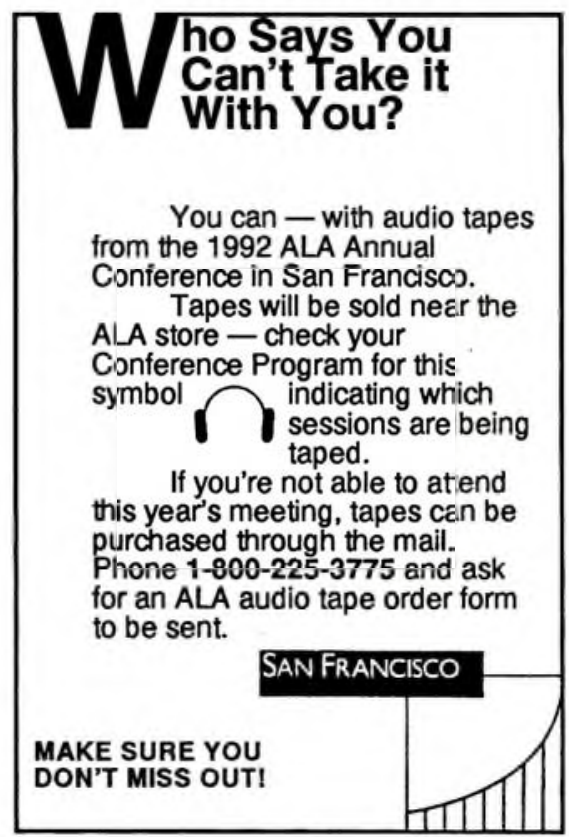

